\title{
Appendix 1: Rich Case Record
}

\section{(C) 2012 Mark Widdowson}

\section{Section 1: Background/Ethical Issues}

\section{Confidentiality}

In order to preserve the client's confidentiality some of the client's biographical details have been disguised.

\section{Consent}

The therapist raised the option of Peter participating in the research during their initial contact, and gave Peter an information sheet about the research and an informed consent form. Peter was aware from the outset that the therapy was part of a research project. Verbal consent was sought at every session for audio recording, and the informed consent procedure was repeated at the end of the therapy. Peter has also reviewed the client description and description of the therapy process and has given his consent for these to be included in the research and used for the purposes of publication.

\section{Therapist competence, treatment integrity and} adherence to TA model

The therapist conducting this psychotherapy was a qualified (CTA) transactional analysis psychotherapist with over 5 years of post-qualifying experience. The therapist had supervision once a month on their work with this client, and their supervisor completed an adherence checklist form after each supervisory contact to confirm the therapist's adherence to a TA psychotherapy approach. All of the therapist's selfcompleted adherence checklist forms (completed after every session) and the supervisor's adherence checklist forms confirmed either 'good' or 'excellent' application of specific features of TA therapy for the treatment of depression, suggesting the therapy was consistently and coherently delivered at a high level of competence and was identifiable TA psychotherapy.

\section{Context of Therapy}

Peter had weekly, individual psychotherapy with a therapist in private practice. Although his therapy was private, he paid a reduced fee.

\section{Section 2: The Client}

\section{Client Description}

Peter was a 28 year old man who lived alone, but near to several family members. At the time of entering therapy he was single, and had been unemployed ever since being made redundant two years previously. Peter had been educated to degree level. He had been diagnosed with depression by a psychiatrist five years earlier, and was not on medication, although he had been prescribed antidepressants previously but had discontinued these 9 months prior to starting therapy due to their side effects and lack of impact on his mood. He had previously engaged in brief Cognitive-Behavioural Therapy (CBT), but this had been discontinued as he did not respond to the treatment and the therapist recommended he seek psychotherapy. His general health was good although he reported very poor selfcare and sleep disturbance, alternating between insomnia and hypersomnia. Peter is the youngest of four children. One sister and one brother live close to him and he sees them several times a week. His other sibling lives in a different city and they have little contact. Peter and his sister both acted as the main carers for their elderly and infirm father. Peter's mother had died when Peter was 13 years old.

Although he reported having a reasonable number of friends and acquaintances, he presented as being fairly socially isolated, seeing people infrequently. Peter had been bullied throughout school and had felt dominated through his childhood by his strict father. Peter recalled being in shock immediately following his mother's death and being told by various family members that he 'had to be strong and be a man now'. Consequently he has no recollection of any grieving.

He presented for therapy being aware of holding many buried feelings which he felt sure were driving his depression, but feeling unable to access them and feeling disconnected from feelings in general other than a sense of sadness, despair and hopelessness. 


\section{Strengths}

Peter was an intelligent, reflective and articulate young man with evidence of strong psychological mindedness. His previous experience of therapy had 'primed' him in terms of his expectations of therapy and the process of therapy. He was well-read and informed about psychology and psychotherapy. He appeared motivated to change, and had sought out therapy independently, doing quite careful research to find a therapist who he felt would have the necessary skills and experience to help him. He travelled for quite some distance to see his therapist, again suggesting that he was well motivated.

\section{DSM-IV Diagnosis}

The therapist made a DSM-IV multi-axial diagnosis based on data from the initial interview with the client and clinical judgement.

- Axis I - Major Depressive Disorder

- Axis II - No Diagnosis

- Axis III - No Diagnosis

- Axis IV - Problems related to primary support group, social environment and occupational problems.

- Axis V - Global Assessment of Functioning score: 54 (on entry to therapy)
Screening with outcome measures

Peter's clinical score at point of entry to therapy using CORE-OM was 21.76, indicating moderate levels of distress and functional impairment and his BDI-II score was 35 , indicating severe depression. The severity of Peter's depression would have warranted the prescribing of antidepressant medication, however due to his previous experiences of medication he wanted to pursue talking therapy instead and his family doctor was supportive of this choice. For further information on Peter's scores on outcome measures, see the section on quantitative outcome data below.

TA Diagnosis:

Injunctions

- Don't Be Important [your needs aren't important]; Don't Be Close; Don't Belong; Don't Be a Child [be a man]; Don't Be You [you're not good enough]; Don't Feel; Don't (do anything) [whatever you do is not good enough] (Goulding and Goulding, 1979).

- Don't Want [because you don't deserve it]; Don't Feel Successful [inadequacy, sense of inferiority]; Don't Enjoy [anhedonia and a lack of a sense of a 'right' to enjoy life] (McNeel, 2010).

Table 4: Peter's Racket (Script) System (Erskine and Zalcman, 1979; O’Reilly-Knapp and Erskine, 2010)

\begin{tabular}{|c|c|c|}
\hline $\begin{array}{l}\text { Script Beliefs } \\
\text { (intrapsychic system) }\end{array}$ & $\begin{array}{l}\text { Racket Displays } \\
\text { (behavioural interface) }\end{array}$ & $\begin{array}{l}\text { Reinforcing Memories } \\
\text { (interpersonal system) }\end{array}$ \\
\hline $\begin{array}{l}\text { 1. Self: } \\
\text { I am inadequate } \\
\text { I will never be good enough }\end{array}$ & $\begin{array}{l}\text { Observable: } \\
\text { Being 'invisible' } \\
\text { Withdrawal }\end{array}$ & $\begin{array}{l}\text { Childhood: } \\
\text { Bullying } \\
\text { Death of Mother } \\
\text { Lack of praise } \\
\text { Repeated criticism }\end{array}$ \\
\hline $\begin{array}{l}\text { 2. Others: } \\
\text { Are selfish and uncaring } \\
\text { Will reject or criticise me }\end{array}$ & $\begin{array}{l}\text { Internal: } \\
\text { Lack of energy } \\
\text { Problems with sleeping } \\
\text { Guilt } \\
\text { Low self-confidence } \\
\text { Tension } \\
\text { Loss of interest } \\
\text { Poor concentration/ memory }\end{array}$ & $\begin{array}{l}\text { Adult life: } \\
\text { Redundancy }\end{array}$ \\
\hline $\begin{array}{l}\text { 3. The World: } \\
\text { Is an unfair and cruel place } \\
\text { Life has no meaning }\end{array}$ & $\begin{array}{l}\text { Fantasies/ Expectations: } \\
\text { My future is bleak and hopeless }\end{array}$ & $\begin{array}{l}\text { Social/ Environmental: } \\
\text { Current family situation }\end{array}$ \\
\hline $\begin{array}{l}\text { Repressed Feelings/ Needs: } \\
\text { Anger } \\
\text { Grief } \\
\text { Needs for- validation \& significance; } \\
\text { acceptance; confirmation of personal } \\
\text { experience; self-definition; the need to } \\
\text { have an impact }\end{array}$ & & \\
\hline
\end{tabular}




\section{Contracting}

The therapeutic contracts developed in the therapy were exploratory and clarifying contracts (Sills, 2006). Peter's therapeutic contracts related to increasing levels of self-awareness which he identified as being necessary to his change process. Peter also identified the need for therapy that would assist him to contact feelings which he felt were inaccessible to him. He has previously engaged in cognitive-behavioural therapy but had not found this to be effective. In particular the 'behavioural activation' aspects of CBT had been difficult for Peter as he felt he had been unable to make behavioural changes without both developing his self-awareness and identifying and expressing his 'hidden feelings'.

Peter and the therapist engaged in some exploratory and alliance building work in the first few sessions, agreeing in session three on a series of contract goals for his therapy. The contract goals were initially based on the problems Peter identified as areas he wanted to focus on (see problems in Personal Questionnaire data below) and were constructed in dialogue with his therapist. Both Peter and his therapist agreed these were suitable goals and areas of focus for the therapy. Nine separate contract goals for the therapy were identified. These were;

- I want to know 'what makes me tick' and drives who I am

- I want to access and express the 'hidden pain'

- I want a more normal body clock

- I want more consistency in my mood without the 'plummeting down'

- I want to explore my feelings around my mother's death

- I want to explore my feelings of being 'crushed'

- I want to understand and explore the impact my family relationships have on me

- I want to feel OK about myself

- I want to deepen my ability to connect more deeply with others.

Treatment Plan

The basic framework of treatment planning in this case was the ' 12 point treatment formulation' developed by the researcher (Widdowson, 2011). The therapist adapted this by 'tailoring' features of this treatment plan according to the individual presentation, identified problems, diagnosis, process and contract goals of the client.

\section{Section 3: Description of the Therapy}

\section{Process}

The following description of the therapy process was based on the therapist's session notes.

\section{Session 1}

This session was spent mostly in identifying and clarifying a number of Peter's issues and exploring the significance of a number of childhood events and their impact on Peter. In particular, the session focused on the death of Peter's mother, his father's continuous criticism of him and his experiences of being bullied at school.

\section{Therapist interventions and theories}

The therapist mostly used enquiry and empathic responding throughout the session (Erskine, Moursund and Trautmann, 1999; Hargaden and Sills, 2002; Widdowson, 2010). Other key interventions included specification and interpretation (Berne, 1966; Hargaden and Sills, 2002) and some initial contracting concerning the tasks and goals of the therapy (Stewart, 2007). The therapist was also gaining information to compile a racket system diagram, (Erskine and Zalcman, 1979) and the empathic responding was intended to begin the process of deconfusion by facilitating Peter's connection to his feelings and providing a safe therapeutic environment (Woollams and Brown, 1979; Clarkson, 1992).

\section{Session 2}

The session continued from the previous session in exploring Peter's experiences of bullying at school and his father's on-going criticism of him.

\section{Therapist interventions and theories}

During structural analysis (Berne, 1961; Stewart and Joines, 1987; Widdowson, 2010) the therapist noted Peter's experiences of shame, sadness, anger and sense of 'not being good enough' and the critical stance of Peter's father. The therapist drew the ego state model for Peter, explaining where these different experiences might be located (sense of inadequacy located in Child, criticism located in Parent), and explained the concept of dialogue between ego states. The therapist continued the process of deconfusion by encouraging Peter's expression of shame, sadness and anger and empathically responding to these expressions. The therapist also encouraged Peter to resume social activities but did not suggest specific behavioural contracts for extra-therapy activities.

\section{Session 3}

Peter reported he had been socialising more since the last session, which he was pleased about, although he had found it difficult and had experienced urges to withdraw. The session then moved into a discussion around the circumstances and events surrounding the death of his mother. Peter found this difficult due to his memories being obscured. His therapist noted that at times Peter seemed quite emotional but trying to hold back his feelings.

\section{Therapist interventions and theories}

The therapist worked primarily using empathic interventions and normalised and contextualised many of Peter's reactions to his mother's death. The therapist attempted to increase the affective charge in the session, but was conscious of not overwhelming Peter by 'pushing too hard'. The therapist also became aware of the potential that Peter might transferentially be 
unconsciously seeking to please the therapist and 'get it right' to avoid criticism. The therapist identified this possibility through countertransference responses which the therapist concluded might be concordant reactive countertransference (Clarkson, 1992).

\section{Session 4}

Peter spent most of this session feeling angry. He expressed his anger at his sense that the world is an unfair and unjust place and that most people are selfish and uncaring. He expressed ambivalence about expressing his anger- he knew some of his anger was justified, however he expressed a strong fear of being like his father and of his anger being unmanageable and out of control.

\section{Therapist interventions and theories:}

The therapist sought to continue Peter's emotional literacy work (Clarkson, 1992; Steiner and Perry, 1999; Tudor and Widdowson, 2001) and support the expression of his feelings and the deconfusion process. The therapist maintained an empathic stance, and normalised many of Peter's historical emotional reactions. The therapist noted that Peter's sense of the world being an unfair and unjust place and of other people being selfish and uncaring as probably being components of Peter's racket beliefs, but did not challenge these, and instead sought to empathically understand how Peter had come to these conclusions. The therapist also introduced some feedback for Peter relating to the therapist's sense that Peter had a highly developed sense of social justice.

\section{Session 5}

Peter began the session discussing his concerns for a friend of his, Lee, who was experiencing a relationship breakdown. Peter talked about the moral imperative for him to support Lee, regardless of the cost to himself. The session went on to discuss Peter's generalised sense of loss following the death of his mother, and in particular the loss of unconditional strokes and acceptance. Peter recognised that he struggles to accept positive strokes.

\section{Therapist interventions and theories}

The therapist continued an empathic stance and also explained the concept of strokes. The therapist also made an interpretation that Peter attempts to 'keep invisible' to avoid criticism, but in doing so misses out on receiving positive strokes.

\section{Session 6}

Peter began the session by informing his therapist that Lee's relationship had completely broken down and that Peter had invited Lee to stay at his house. Peter expressed strong concern over Lee's well-being and in particular his alarm at the intensity of Lee's distress. He wanted to clarify something from the previous session he expressed that he had been surprised and puzzled by the therapist's positive stroke of 'I look forward to seeing you' and wanted to know why the therapist looked forward to seeing him.

Peter spoke in an emotionally distant manner regarding his sense that the world is an unfair place, and of his experiences of his father's criticism. He spent a lot of this session feeling angry. As Peter became more aware of his anger, he eventually went quiet and the therapist had a sense of Peter withdrawing, suggesting an alliance rupture. The therapist enquired into Peter's experiencing and Peter revealed he was feeling 'a bit angry' towards his therapist because his therapist was stimulating and intensifying Peter's anger.

\section{Therapist interventions and theories}

The therapist's main aim in this session was deconfusion. The material was conceptualised using structural analysis and deconfusion (supporting the expression of the anger Peter held in his Child ego state) and relational rupture/repair, the racket system and the expression of loss underneath the anger and Peter's sense of longing. The therapist also drew Peter's attention to Peter's tendency to automatically reject or discount positive strokes.

\section{Session 7}

Peter once again began the session by discussing the situation he was in with his friend, Lee. Lee had spent all of the previous week alternating between crying and despair and hostility, which had often been directed at Peter. Peter intellectually knew that Lee was hurting and just 'lashing out', but was finding it extremely difficult to manage the feelings of inadequacy that Lee's criticism and hostility stimulated. He recognised that he had emotionally deteriorated over the past week (see CORE-10 scores) but was able to rationalise this deterioration as being related to the stressful situation he was in. Peter also expressed that whilst intellectually he knew he was doing what was right and therefore had a sense of being 'a decent person', he could not at present experience this emotionally as a sense of being 'OK'.

\section{Therapist interventions and theories}

The therapist identified and clarified a number of existential issues Peter was struggling with as well as Peter's need to live his life according to his own morals and values. The therapist raised with Peter his sense that there had been a number of alliance ruptures in the early part of the session where the therapist had kept misunderstanding Peter. He invited Peter into a discussion regarding his experience of being misunderstood by his therapist. The therapist supported Peter in expressing his sense of irritation towards his therapist for the misunderstandings and empathically responded and normalised his irritation. The therapist used principles of Inquiry, Attunement and Involvement (Erskine 1993) throughout the session. 


\section{Session 8}

The therapist began the session by reviewing the therapy so far. Peter expressed that he was happy with the way the therapy was going, and that he wanted to continue to focus on his originally identified problems and contract goals. The session continued with exploration into Peter's relationships with his family members, and the impact of their subtle but continuous criticism of Peter.

\section{Therapist interventions and theories}

Following the re-contracting and review process, the therapist focused on Peter's 'I'm Not OK- You're OK' life position and how the interactions with his family members provided many negative strokes. The therapist noted Peter had begun to question the validity of the criticism and stroked Peter's emergent sense that he needed to follow his own path in life and life according to his own 'moral compass'. The therapist also supported Peter in identifying, questioning and ultimately rejecting unfair and unjustified negative strokes.

\section{Session 9}

The session focused on how Peter had begun to recognise the extent of criticism and negative strokes he received from his family members in various interactions over the previous week.

\section{Therapist interventions and theories}

The therapist explained the concept of cumulative and relational trauma to Peter (Erskine, Moursund and Trautmann, 1999; DeYoung, 2003). The therapist also noted a number of Peter's relational needs emerging in the session - particularly his need to express his gratitude towards the therapist. The therapist continued to support Peter in identifying, questioning and rejecting unfair negative strokes and how the transactions with his family members activated a self-critical Parent-Child internal dialogue accompanied by Peter's sense of inadequacy.

\section{Session 10}

This session almost exclusively focused on a number of existential themes which Peter was experiencing (see HAT and transcript- highly important session), and in particular how they linked to his script and the games (Berne, 1972; Stewart and Joines, 1987) he was drawn into.

Peter began to express a sense of understanding and forgiveness towards his father for his criticism and expressed his appreciation that his father had clearly struggled with his own feelings of grief following the death of his wife and how this had obviously impacted on his ability to emotionally take care of his grieving son. The therapist had a strong sense that Peter's understanding, forgiveness and acceptance was congruent and appropriate.

\section{Therapist interventions and theories}

Towards the end of the session, Peter began to express his gratitude to his therapist, but stopped and looked at his therapist. The two of them sat in silence for a moment, experiencing an 'intersubjective moment of meeting' (Stern, 2004) - both implicitly understanding each other and experiencing a strong sense of connection.

\section{Session 11}

The session initially continued with exploration into how subtle criticism would lead Peter into self-doubt and self-criticism. This exploration followed Peter discussing the feelings he had been left with following a confrontation with his brother where Peter challenged his brother's criticism of him, but was left doubting himself afterwards. The therapist explained the concept of social and psychological transactions to Peter, and how Peter's critical Parent ego state was activated at such times. Peter contacted his Child feelings of despair and hopelessness during such instances and his desire to withdraw.

Therapist interventions and theories

The therapist was keen to deepen the deconfusion process by seeking to develop Peter's affective tolerance and affective regulation in this session, so invited Peter to 'stay with his feelings' whilst maintaining empathic contact with Peter. The therapist supported the deconfusion process by inviting Peter to express his sense of inadequacy, shame and his desire to withdraw during and following experiences of criticism.

Three days after the session, Peter e-mailed his therapist with the following:

I've been reflecting on my fundamental feelings of inadequacy. I think I have had some insights that I think may be correct but l'd like an outside perspective to judge whether my insights and views are reasonable. Whilst I understand it's more important whether I think it's reasonable, I know that emotionally I need to compare my considerations to someone else's opinion in order to feel like I'm being fair and not just deluding myself. So, in light of this, does this seem like a fair appraisal of my situation?

I have deep-seated feelings of inadequacy. I feel this way because: nothing I have done has ever been good enough; Because - when it has been good enough nobody has ever communicated to me that it was; Because they held me to impossible standards; Because they did not have sympathy for my situation; Because my family do not communicate with subtle indicators of their care and concern and because often they have told me I wasn't good enough. These feelings hurt me because I am sorry for my inadequacy. I care about the opinions of others and everyone genuinely matters to me.

Conclusion: I assumed a degree of sympathy and care in other people that wasn't there, because those feelings are natural - fundamental - to me. When others held me to standards that it was impossible to satisfy, I 
assumed that this was because of an inadequacy on my part, rather than realising that they lacked the sympathy and care to realise that their standards were inappropriate to me. I have never been inadequate: the expectations of me have been inappropriate, and the people who placed them on me were inadequate in their sympathy and care.

\section{Session 12}

The session began with Peter and his therapist discussing Peter's e-mail and the therapist supporting Peter's analysis of his situation and the life experiences which had contributed towards his sense of inadequacy. Peter continued to challenge and reject this sense of inadequacy and the associated script decisions.

\section{Therapist interventions and theories}

The therapist supported Peter's analysis of interactions using analysis of transactions and game analysis as theoretical frameworks. The therapist used heighteners (McNeel, 1976) to support Peter in his expression of 'I am not inadequate' and to promote a redecision. The therapist noted an experiential sense that Peter was indeed experiencing himself as being 'good enough' and reflected this back to Peter.

\section{Therapist hypothesis of the therapeutic process}

In evaluating his life experiences, Peter began to question the behaviours of others towards him. In doing so, he got angry and was encouraged in the session to express his anger. This directly challenged his Don't Feel injunction, and also was part of the deconfusion process of expressing the underlying repressed feelings which fuel his racket system. Peter experienced the therapist's empathy and used the sessions to assist with emotional regulation (exposure?) and in doing so decontaminated fears of being out of control. The expression and validation of his anger (by a supportive 'other') enabled him to 'complete the cycle' and 'deal with unfinished business' and so move through a cycle of grief and to acceptance (Clark, 2001). This enabled Peter to examine and re-evaluate his script decisions (inadequacy) and to make a spontaneous redecision.

\section{Session 13}

Following an unexpected two week break in sessions due to the therapist being ill, Peter returned to therapy feeling 'in a dark place'. He had contacted some feelings of destructiveness and a sense of being deserving of pain and undeserving of recovery and peace. Although he recognised the feeling as being long-standing in nature, he wondered if this experience had been triggered by the possibility of recovery.

\section{Therapist interventions and theories}

The therapist maintained an empathic stance, and worked 'indirectly' with understanding the feelings, as opposed to Peter's desire to 'know where it comes from' by direct questioning. As Peter would often respond quite rapidly, the therapist invited him to slow down and pause before responding, to 'make space' for the 'hidden feelings' and to enable Peter to become aware of the ego state dialogue which was just at the edge of his awareness. The therapist understood the problem as being a repressed feeling of futile rage and hostility, held in Child (possibly associated with experiences of childhood bullying) and an internalised punitive Parent, composed of many figures from Peter's past. The therapist invited Peter to develop a compassionate stance in relation to the hurting, angry Child ego state and to attempt to 'understand the sense of anger held in that part of you'. The therapist viewed the work to be structural analysis incorporating deconfusion of the Child.

Peter's CORE scores at the beginning of the session showed a marked increase from the previous session, which the therapist understood to be representative of Peter's deconfusion process and associated with the emergence and awareness of the 'hidden' distressing feelings. The therapist also considered the intensification of Peter's critical Parent messages as being a script backlash process, whereby Peter was challenging his script which in turn activated introjected prohibitions in his Parent.

\section{Session 14}

Peter's CORE scores had dropped quite significantly from the previous week's elevated scores, which the therapist considered to confirm their hypothesis about Peter's distress at the beginning of the previous session as being a script backlash reaction. Peter had found the understanding of his internal process and ego state dialogue in the previous session to be helpful, and wanted to continue his session exploring this process and re-evaluating the 'voices' of the dialogue as he had begun to question the validity of the harsh Parental messages he experienced. He went on to link the Parent 'voice' to experiences where he had been dominated in power-plays, and he explored the impact of power-plays on him in his day-to-day life. The session concluded with a discussion around existential issues of meaning and meaninglessness.

\section{Therapist Interventions and Theories}

The therapist continued with some structural analysis and moved to impasse clarification work, by inviting Peter to be aware of the 'battle between the two voices'. The therapist sought to intensify the strength of the 'fight back' in Peter's Child, and also to support Peter's Adult ego state to identify, re-evaluate and begin to reject the Parental critical voice. The therapist sought to validate Peter's awareness of power-plays and loaned Peter some reading material by Steiner (Steiner and Perry, 1999) which discussed power-plays. The therapist engaged with Peter in his discussion of existential issues, and occasionally provided a 'devil's advocate position', to invite Peter to evaluate where aspects of the critical ego state dialogue and his script beliefs 
maintained a position of despair and to promote Peter's sense of choice over his destiny. The therapist felt that the session felt very 'full' and that a lot of ground had been covered which would promote Peter's capacity to resolve the impasse and make a redecision. This view was supported in an e-mail the therapist received several days after the session, where Peter described reflecting on the session and deciding he was no longer going to 'accept the tyranny of the Parent' and that he 'understood and forgave his child'. He described using his Adult ego state to identify and reject the critical Parent dialogue.

\section{Session 15}

Peter began his session excitedly telling his therapist about a social event he had arranged. Following his decision to reject the critical Parent dialogue, he contacted several friends and invited them to a dinner party at his home, which had been successful. Peter felt this was symbolic of his internal 'shift' as previously he had not initiated social contact or arranged events. The session continued with Peter discussing his desire for a sense of deep connection and acceptance from others, but recognising the limitations of achieving this given his current social and familial circumstances. He discussed his sense of needing to keep certain thoughts and feelings out of relationships as they would not be understood or accepted. This 'shutting out' was in order to prevent an experience of rejection and so confound his sense of alienation, and he recognised that, ironically, this kept him out of full relational contact with others. He went on to want to explore the possibilities he has for being able to obtain intimacy with others. The session finished with some discussion regarding termination of the therapy and Peter expressed a wish to have 'maintenance' sessions after the period of research therapy had been concluded.

\section{Therapist Interventions and Theories}

The therapist continued to maintain an empathic, inquiring stance in order to help Peter articulate his feelings of disconnection and longing for intimacy. From the perspective of a relational approach, the therapist understood Peter's sense of needing to keep aspects of himself out of his relationships, but combined this with classical TA methods to help Peter understand the internal and interpersonal processes involved in relational disconnection and connection. The activation of Peter's desire for intimacy was viewed by the therapist as indicative of the activation of Peter's physis (Berne, 1972; Clarkson, 1992) and suggestive of a resolution of the impasse (Mellor, 1980) Peter previously experienced and an implicit redecision that he was now 'good enough' to enter into relationships. Peter expressed a sense of despair about being able to 'work out how to connect' to people, as he had tried many times previously to express himself and had either not been understood or had been dismissed or rejected. The therapist offered Peter the suggestion that maybe he might need to find a way to communicate his inner experience on this deep level using the language of the person he was speaking to, adjusting his transactional stimulus in order to maximise the potential for an intimate and accepting response. This approach was a revelation to Peter who described it as a 'eureka moment'.

\section{Session 16}

Peter wanted to spend the session addressing some issues which he felt were connected and which he felt contributed to a number of the problems he experienced. He expressed that their resolution would be important in ensuring his continued progress. He described feeling that he struggled with managing stress and wanted to explore strategies for stress management. He also described that although his mood was much more stable that it had been prior to therapy, he often experienced a sense of anhedonia which impacted on his motivation, focus, concentration and capacity to experience relational contact with others. The therapist and Peter also made arrangements for Peter's follow-up interview and for the maintenance therapy sessions now the main phase of the therapy had been concluded.

\section{Therapist Interventions and Theories}

The therapist understood Peter's growing sense of 'wanting more' as being indicative of an impasse - he was now more acutely aware of his emotions and his responses to situations, and was aware of a growing desire for more relational contact with others, but felt somehow prevented from obtaining what he wanted and needed. The therapist worked using impasse clarification and invited Peter to be more aware of the 'push-pull' of the impasse in his daily life. The therapist also raised the issue of 'permission' (Crossman, 1966) with Peter and invited Peter to reflect upon and notice if he experienced an internal sense of having permission to enjoy and engage with life with the hope that Peter would be able to continue this work by himself and if, by being able to give himself permission to enjoy, he would mobilise internal strength to resolve the impasse spontaneously. The therapist also recommended that Peter learn mindfulness meditation as a method to help him to manage stress and improve his concentration and gave Peter some recommendations for books about mindfulness to help him maintain and strengthen his gains in therapy.

Transference and countertransference issues - the therapist's reflections

The therapist noted that at first Peter presented as rather reserved and wondered if this was in part due to Peter's expectations and previous experiences of therapy and in part due to a general sense of reserve in relationships. The therapist speculated that it was probably a combination of both. During the initial sessions, Peter often expressed his gratitude to his therapist, which the therapist understood as an important expression of his relational needs (Erskine 
and Trautmann 1996) or perhaps as an indicator Peter was 'taking in some emotional nourishment' from the therapy perhaps via introjective transference (Hargaden and Sills, 2002). The therapist also was under the impression that in the first half of the therapy Peter had an underlying expectation that he would be criticised, emotionally attacked or rejected. The therapist commented that this impression seemed to dwindle in the second half of the therapy process, which may be significant in relation to Peter's improvement in the latter sessions.

The therapist's countertransference towards Peter was benign and positive - the therapist liked Peter and enjoyed his intelligence and caring nature. The therapist reported in the early part of the therapy having a strong sense of 'wanting to get it right' with Peter. It is possible this might be some concordant countertransference (with the therapist identifying with a similar process in Peter's psyche) or could have been related to the demands of participating in the research and a sense of exposure and scrutiny of their work.

Additional comments on the therapist's approach Peter had initially reported that his previous CBT (which by all accounts was delivered by a competent therapist) had been ineffective so his TA therapist avoided techniques which might be considered analogous to CBT, such as 'behavioural activation' (behavioural contracting) and 'thought challenging'. As his therapist tends to work more relationally, this adjustment was relatively straight-forward. The exception to this is Peter's therapist gave him a handout relating to 'sleep hygiene' to assist with Peter's problems with his body clock, although Peter's implementation of the sleep hygiene methods was never discussed in therapy.

\section{Section 4: Quantitative Outcome Data}

\section{Measures Used}

For the research Peter completed a number of detailed quantitative and qualitative measures at initial screening, after session 8 , and at the end of therapy. The measures used were CORE-OM (Barkham et. al 2006), the Beck Depression Inventory-II (Beck, et al. 1961; Beck, et al. 1996) and a simplified Personal Questionnaire (Wagner and Elliott, 2004). Peter also completed weekly monitoring using the CORE-10 (a validated screening measure which has good correlations with CORE-OM scores) and the simplified Personal Questionnaire to monitor his progress in therapy, as well as completing the Helpful Aspects of Therapy measure (Llewelyn, 1988) - a qualitative measure where the client indicates what was helpful to them in the therapy session.
Editor's Note: Table 2 and Figures 1 and 2 referred to below are included in the main article so are not reproduced here.

The quantitative outcome measures were analysed for clinical significance to indicate whether the client demonstrated clinically significant change indicating a movement from a clinical to a non-clinical score (Jacobson and Truax, 1991). Movement to a nonclinical score is indicated by ++ . In Table 1: Peter's Outcome Data and Figure 1: Weekly CORE-10 Monitoring Data, 'caseness cut-offs' indicate the score needed for inclusion in the study. Where the client's score is in the clinical range, the score is highlighted in the table in bold. An indicator was used for a Reliable Change Index, to measure whether the client had achieved reliable change.

\section{Personal Questionnaire Data}

An adapted version of the simplified Personal Questionnaire (Wagner \& Elliott, 2004) was used to identify the main problems the client wished to resolve in therapy. During the intake interview the client identified the severity of each problem using a 7 point Likert scale, whereby a score of one indicates that the problem is not causing the client any distress at all through to 7 whereby the problem is causing the client the maximum distress possible. The client completed this main $P Q$ problem severity rating form at the beginning of each session to allow for monitoring of the client's progress through the therapy. The clinical cut off for this measurement is the value 3.5 and scores greater than this are considered as being in the clinical range and causing the client distress. Scores of less than 3 are problems which are causing the client little distress. The mean PQ scores across therapy can be seen in the table 5 below. Scores which are in the clinical range are highlighted in bold (Figure 2).

\section{Section 5: Helpful \& Hindering Aspects}

\section{of Therapy}

The Helpful Aspects of Therapy form (Llewellyn, 1988) was completed by the client at the end of each session. The form asks the client to describe what aspects of the session or particular events within the session were most helpful or meaningful. The form asks the client to rate these aspects of event using a 9-point Likert scale where 9: extremely helpful and 1: extremely hindering. In this case analysis is reported only of the items which were rated as moderately, greatly or extremely helpful.

The mean session rating was 7.78 'moderately-greatly helpful'. In the client's weekly HAT forms, two sessions were rated as 'neutral'. No sessions or episodes within sessions were rated as 'hindering'. 


\begin{tabular}{|c|c|c|c|c|c|c|c|}
\hline & $\begin{array}{l}\text { Duration of } \\
\text { the } \\
\text { problem }\end{array}$ & Pre & Mid & End & $\begin{array}{l}1 \\
\text { month } \\
\text { Follow } \\
\text { up }\end{array}$ & $\begin{array}{l}3 \\
\text { month } \\
\text { Follow } \\
\text { up }\end{array}$ & $\begin{array}{l}6 \\
\text { month } \\
\text { Follow } \\
\text { up }\end{array}$ \\
\hline 1. I don't know what makes me tick & $>10$ years & 7 & 4 & 4 & 4 & 3 & \\
\hline 2. My body clock is very disrupted & $6-10$ years & 6 & 6 & 4 & 4 & 5 & \\
\hline 3. My mood is inconsistent & $>10$ years & 5 & 4 & 3 & 2 & 3 & \\
\hline 4. I don't feel OK about myself & $>10$ years & 6 & 6 & 4 & 4 & 1 & \\
\hline $\begin{array}{l}\text { 5. I am not sure how my family relationships } \\
\text { impact on me }\end{array}$ & $>10$ years & 7 & 7 & 2 & 2 & 2 & \\
\hline 6. Disconnected from my feelings & $>10$ years & 7 & 4 & 1 & 1 & 1 & \\
\hline $\begin{array}{l}\text { 7. Problems with memory \& concentration [item } \\
7 \text { added by client at session 2] }\end{array}$ & $6-10$ years & 5 & 2 & 1 & 1 & 1 & \\
\hline
\end{tabular}

Table 6: Helpful Aspects of Therapy

Rating key: Extremely (9); Greatly (8) or Moderately (7) Helpful

\begin{tabular}{|c|c|c|}
\hline $\begin{array}{l}\text { Session } \\
\text { no }\end{array}$ & $\begin{array}{l}\text { Helpful aspect/ } \\
\text { What Made it Helpful }\end{array}$ & Rating \\
\hline 1 & $\begin{array}{l}\text { When the therapist said 'the word that } \\
\text { comes to mind is crushed' it put a lot of my } \\
\text { feelings into perspective and put my problem } \\
\text { into stark relief in a very raw, but helpful } \\
\text { way. It made me admit/acknowledge } \\
\text { something I couldn't see on my own. }\end{array}$ & 8 \\
\hline 2 & $\begin{array}{l}\text { Admitting/explaining my perspective and } \\
\text { intentions in the bullying incident. l'd never } \\
\text { admitted it before, never felt that l'd be } \\
\text { believed and something old and sore and } \\
\text { forgotten brought to the surface. } \\
\text { Parent/Adult/Child model explanation }\end{array}$ & 7.5 \\
\hline 5 & $\begin{array}{l}\text { Realising that my family hasn't conveyed the } \\
\text { feeling of their unconditional support and } \\
\text { love. Helps me to understand what makes } \\
\text { me tick. }\end{array}$ & 8 \\
\hline & Discussion of my withdrawn nature & 7 \\
\hline \multirow[t]{2}{*}{6} & $\begin{array}{l}\text { Expressing/ understanding my fundamental } \\
\text { drive of anger and awareness of the break } \\
\text { that makes it: self-knowledge }\end{array}$ & 9 \\
\hline & $\begin{array}{l}\text { Improving my therapist's understanding of } \\
\text { me - it's nice to be understood. }\end{array}$ & 6 \\
\hline 7 & $\begin{array}{l}\text { Elaboration of my emotional needs } \\
\text { regarding fulfillment in life. Felt like it laid } \\
\text { groundwork for later sessions. }\end{array}$ & 7 \\
\hline 8 & $\begin{array}{l}\text { Reassurance of the validity and correctness } \\
\text { of my criticisms of both my family and } \\
\text { society, and of my response to these. The } \\
\text { reassurance helped me maintain objectivity } \\
\text { and perspective. }\end{array}$ & 9 \\
\hline
\end{tabular}

\begin{tabular}{|c|c|c|}
\hline & $\begin{array}{l}\text { Bringing the elements of my family dynamics } \\
\text { into focus }\end{array}$ & 7 \\
\hline 9 & $\begin{array}{l}\text { Deciding where to go next. Direction is good } \\
\text { as I felt aimless today. }\end{array}$ & 7 \\
\hline 10 & $\begin{array}{l}\text { Admitting my conception of who and how I } \\
\text { am, my drive for literal altruism at personal } \\
\text { cost. It's an expression of who I am, and an } \\
\text { acknowledgement of my 'uncomfortable sanity'. } \\
\text { It's the basis for who I will choose to be. }\end{array}$ & 9 \\
\hline 11 & $\begin{array}{l}\text { Achieving the goal I had for the session- } \\
\text { finding an experiential approach that will let } \\
\text { me find a method of coping with emotions. } \\
\text { It's inherently good, as it will be useful, and } \\
\text { it's satisfying to achieve. }\end{array}$ & 9 \\
\hline 12 & $\begin{array}{l}\text { Recognizing that strokes containing the } \\
\text { criticism of 'you're inadequate' set off my } \\
\text { depression. Helps me to look for, identify } \\
\text { and reject these strokes. }\end{array}$ & 8 \\
\hline 13 & $\begin{array}{l}\text { A deconstruction of the probably } \\
\text { psychological reasons behind my feelings. } \\
\text { Understanding. }\end{array}$ & 7 \\
\hline 14 & $\begin{array}{l}\text { The discussion; it feels like groundwork for } \\
\text { future resolution. I got a feeling of progress. }\end{array}$ & 8 \\
\hline 15 & $\begin{array}{l}\text { Recognition of a deficiency in my } \\
\text { interpersonal skills and the suggestion of a } \\
\text { new approach. It gives me a way forward, to } \\
\text { express myself with the confidence that I } \\
\text { might be understood. An instant- "eureka!" } \\
\text { Clarification of my position in my family. }\end{array}$ & 9 \\
\hline 16 & $\begin{array}{l}\text { Realising that the negative part of my } \\
\text { personality has a block on my positive } \\
\text { feelings. Knowing this, I can work against it. }\end{array}$ & 9 \\
\hline
\end{tabular}




\section{Section 6: Change Interview Data}

The client participated in two follow-up Change Interviews; one interview two weeks after concluding therapy and the second interview three months after concluding therapy. The Change Interview protocol invites the client to reflect on the therapy and to identify specific changes they experienced during the course of therapy. The client is invited to comment on the mechanisms of those changes and what they attribute those changes to. The data in Table 2 (main article) relates to changes the client identified in his first followup interview.

\section{Helpful Therapy Processes Identified in Follow-up} one Change Interview

C3: Possibly one of the most positive experiences of my life, I'll be totally honest. It's made a huge difference to me. I feel much better and it's been possibly the most supportive and confidence building, rebuilding experiences I have ever had. Primarily, for me anyway it's been confirming a lot of stuff that l've often felt where (my therapist) has been able to contextualise or put into words and what it's been for me more than anything been a way for me to clarify both my problems and what makes me tick, and how those two things feed each other in a way.

R12: So was there anything in the therapy that helped you, or encouraged you set aside those inhibitions and also I'm wondering if there's anything that happened or was a factor that might have encouraged them to stay? If you see what I mean

C12: I know what you mean. I don't think there was anything in therapy which encouraged inhibitions in communication at all. Not in the slightest. [My therapist has] been incredibly good. I mean, I don't mind saying this and I'm not meaning to compliment [them] but for the record for the tape [they] have been incredibly good at putting me at ease and l'd say that honestly, one of the things that have made a huge difference to me is, the fact that when my time-keeping has not been great, [they have] been accepting of that and not made a big deal about it. Even when l've meant to have a much shorter session [they were] usually ok about it and just kind of been fine with it. That has made the biggest difference in the world to me... And similarly, [their] mannerisms in general. [My therapist is] very good at not just talking but kind of contextualising, and feeling through things on behalf of people to a little extent. At least helping them to feel through it. All that sort of stuff altogether has been tremendously good for me. [My therapist has] also shown a general interest and kind of assisting with things like lending me some books... All that stuff has made a difference, the human element essentially. [they may have been] my therapist but I also feel that they were being genuine as a human being.
C13: Yeah, I say that also, for me, again I don't know how this will be applicable for others, but for me I have a very, very low tolerance for feeling that I have been managed or kind of that I am being socially manipulated or anything at all like that. I mean even if someone hates my guts I infinitely have more respect for them if they are honest about it. I have almost never, I think there's only one occasion I have ever felt that [my therapist was] managing me slightly. Almost all the time [they have] been entirely genuine and open and honest and that's been great. The only time I ever felt [they] were a little bit like that and that's me being a bit paranoid. I mentioned to [them] at the time which was, I think it was about something arranging a session or... [item removed due to confidentiality]. I just said that I thought [they] were being a little 'salesman like' there and to be totally honest in retrospect I don't think [they] even were. I think I was just me being paranoid as I'm used to it from other people. Yeah, fundamentally that honesty, that interpersonal honesty is the greatest thing, you know? I will say this, if [my therapist does] have like particularly strong different opinions or anything else that [they have] held back, [they've] one it so perfectly that I have been completely oblivious to.

C15: I would say that primarily [my therapist has] seemed interested, you know, [they have] been actively engaged in what's going on with me. Even when it hasn't always been, you know, on my part I haven't been on my best or at my nicest or even like I say stupid shit which I mean well but completely phrase in the wrong way or similar. [My therapist has] been interested and engaged and it's that engagement, that being interested, that genuine kind of sense of care. You know I have the impression that [they] have a regard for my mental well-being.

C16: as l've more emotionally opened up and recovered during therapy I have felt that, I do feel that [my therapist has been engaged and does actually care and that has made the biggest difference l'd say in opening up. 'Cause I mean you can't open up to someone who doesn't seem that they genuinely care.

C17: ...You know, but when you have someone who apart from all the clinical stuff, [does] seem engaged clinically and intellectually yes definitely but [they] seem like that on some level emotionally or interpersonally engaged and that l'd say is the biggest factor. It's that interest and engagement. l'd like to say that it can't be faked, maybe it can, I don't know, but it certainly I think is probably the most important part for me.

C42: ...Therapy has been breaking those contextual associations and breaking that model and showing other avenues and ways of being which then allows new experiences to be interpreted in a new and different light, which can lead to older experiences being re-interpreted. 
R82: I'm very curious about what specific bits of therapy have been most useful?

C82: The things that have told me about myself and how I tick. I somehow found when I first came in, I think that's probably been the most important one I put down there and even the other things on the list like my interpersonal changes all of those fall under that fundamental change in. I don't want to be clichéd and 'know thyself' and all that sort of nonsense but at the same time, yeah, it is true

R83: So it's something about self-awareness and selfunderstanding?

C83: Yes, if you know about yourself and can understand yourself, including the part of yourself that is depressed that allows you to make progress and to make changes. 'Cause without knowledge, again it's the idea about, before I came I was pretty blind to possibilities but I learned about myself. That gave me the ability to see other ways of being, other ways of doing. It's that kind of being armed. It's like if you can't see something, can't perceive something it might as well not be there, you can't do anything about it. As I learnt about myself, and that includes how my family impacts on me, all the things that make me tick. I was then able to make changes. Some of it was slow, some was difficult, some of it was painful but the point is that it is that self- understanding.

R84: So, can I just check I'm understanding you right? Something about contacting things that were hidden? Contacting parts of yourself that were hidden that has been quite important?

C85: Yeah, l'd say that the main thing about it is that it's bringing things out into the open so that they can be dealt with. It's not just bringing individually things out. 'Here is this component let's deal with it' but also a knowledge of self, what makes me tick etc has facilitated that and allowed me to make those changes. That I would say is the most fundamental thing that I have got from therapy.

C86: Now, as for things [my therapist has] done, see, I can't think of any particular incidents that stand out beyond the fact that where there has been instantly [my therapist has] brought something into focus and l've had a kind of epiphany sort of moment those have brought major changes. If you're asking what [my therapist has] done to contribute to that I can only... their skills as a therapist and I don't know enough to be able to analyse that. This isn't a very helpful answer in terms of research but I can't think of anything direct. The supportive and nurturing almost if you will of part of the therapist client relationship that we have going has facilitated it to happen but in terms of individual stuff [my therapist has] done where I can go yes that was really good. I can't think of anything in particular that stands out. It may be and I don't mean this as a compliment I mean this as a natural form. It may be that actually [my therapist is] just so good essentially that all the stuff [my therapist has] done as a therapist has been equally contributive and equally good.

C87: I'd say that, it was something I touched on before the supportive part that things didn't just kind of necessarily end with just the therapy sort of material. It didn't feel clinical. It didn't feel like [they were just] turning up for this time slot and I'll set this time slot and all the rest of it. There was a couple of times l'd sent a text outside, similar [and my therapist] replied to them. Lent a book. This sort of stuff really mattered. I'd say that in fact that without that stuff none of the other gains made would have been possible because the communication wouldn't have been possible and the honesty, the interpersonal honesty that l've been trying to do, wouldn't have been possible. l'd say that matters. l'd say that would be the most important. l'd say part or contributing thing because it's enabled everything else.

C89: A lot of the time, although [my therapist has been] incredibly professional in their interactions, it's not felt essentially as if $\mathrm{I}$ 'm in a professional relationship. Professionally you go to the Doctor and say well Doctor I'm here about x,y \& $z$. you know, and they all have this bedside manner and that enables things. It's not felt as if I'm in a professional environment so to speak, that I'm not having to guard myself and the rest of it and that's been very important. Now, it has been intellectually and where l've said very professional and that the techniques etc have all been professionally administered etc. but it's the subtext - the psychological subtext has been very different. 'Cause [my therapist and I] talked before about there being a message, in the underlying tone. The message has always been professional the underlying tone has been, this is a building relationship. Mostly one way, providing therapy to myself, but you know, there you go

R90: There was something about what you said there I was... want to lead back to something that you said previously to see that I understand. It's like yes there has been a professional relationship but within that there has been a real sense of closeness and interpersonal contact?

C90: Yes, and I would say that it's the most important part I think. Because, you know, you could train any robot to have a knowledge of the techniques etc and maybe able to administer them too with advanced recognition etc. but the interpersonal human component which, again the human component is the emotional component, there is no separating the two, that's what makes therapy possible I think. I can't really take someone's advice, take their opinions, take their lessons if you don't feel they're engaged, you don't feel they're interested 
Unhelpful Therapy Processes

Peter did not identify any therapy processes or aspects of the therapy that were unhelpful in either his weekly HAT forms, or in his follow-up Change Interview.

Difficult but potentially helpful therapy processes C7: ...So at first it was very difficult to open up about some things inside and it took a lot of effort to get going at first or at least in retrospect it didn't take a lot of effort but maybe felt like it was more at the time. 'Cause talking to someone frankly and openly and to have them concerned about your mental well-being is very alien. It's alien to people in general. It's very strange but over time it's been one of the things that I look forward to. Even on days that I have nothing compulsive to talk about and I have nothing urgent that I need to deal with. It's been very supportive and for me has made a huge personal difference and I think, yeah, that's it in a nutshell. Difficult at first and a couple of times l've had to, especially at the start when I was at a much worse place and much lower motivation, had to make a bit of an effort to get myself going but over time that eased up.

c92: There's certainly been nothing that has been disappointing. I can say that with honesty. I don't think I'm looking back through rose tinted glasses when I say that. 'Cause even times when I have been to therapy and it feels like nothing has particularly happened at that session l've even said at the time I felt like it was building or ground work, I don't think that... Now, as for other stuff which l've felt... There's been sessions where l've burst into tears or had to admit difficult facts about myself and the rest of it but I wouldn't say that they were especially traumatic in themselves in these events.

Incomplete aspects of therapy

C31: [in response to a question about how the client sees himself now] (Pause) A good guy and that's all I can say for certain. I still have a kind of empathic blind spot about how other people view me. I think it's partly 'cause I don't know myself I can't really begin to predict how others might view me. I could pull up a whole bunch of names and such but I don't necessarily believe that anymore. But I just don't know. That's being honest, and I'm not troubled by that. I think it's probably positive for the most part. I just don't know.

C33: I could give this also perfect answers where it would be 'I would remove my vice impulses' and all that kind of stuff but honestly l'd like to improve my concentration. My ability to stick on top of, things, my endurance. To stay at a task from day to day. That's the only thing I would change about myself right now and I am in the process of changing it. Other things about myself, nothing that cannot be easily fixed, or at least, kind of corrected a bit. You know?

c94: Well, I would, it's something that really feel it should be touched on because it's kind of... it's one of those things that I said that totally should do this and then other stuff and it was a different time and basically therapy has all worked fine and I think the only reason it didn't cover it was time constraints which is I think at some point is going to be good to go back and look at my past, particularly events from my mum's death etc and some of the pain and stuff there. So I think I'm still carrying that inside and it's not a source of distress to me but I think it's something I need to kind of unearth, keep out and kind of deal with.

C96: We have touched on that in quite more depth and we haven't necessarily about my mum and her death. But nevertheless there is still an element of sadness there, an element of distress which hasn't been touched yet and the other outside bit, the therapy block we did, the other therapy has going to be touched on. That's the only thing I would say. The only reason it didn't get touched on was time constraints.

Helpful \& Hindering Factors in client's life situation Peter did not indicate any helpful factors in his life situation. His therapist stated that Peter did often indicate that his unemployment, initial social isolation and on-going experiences of criticism by his family were hindering factors for him.

Client's Personal Strengths: (Motivation to change)

(See also client description in section 2 above)

C8: (in response to how client overcame inhibitions and initial awkwardness of therapy) This might sound really simple but I just forced myself. I immediately just said 'damn the consequences' essentially. I mean for a lot of people that's maybe not so easy, and it wasn't particularly for me. I think part of the reason it went well for me was I always say that based entirely of my own volition by taking charge of it... in the past I think part of the problem was I didn't follow what I felt I should to help myself essentially. You know I let other people see me in that regard. I let other people make decisions for me on my behalf for my own mental well-being and when I came to therapy it was me kind of making a decision...

C9: I actually said this seems right for me. And I thought that, well maybe in an alternate universe that if [my therapist] turned out not to be a great therapist I thought well, so what, at least I'll have given it a try. I felt that taking the active role, that was important. Maybe a large part of it was self- determination and the confidence and kind of grounding that gives but that made a huge difference to me. I think that's what made it easier to open up about stuff.

R10: Is there something, if I'm understanding you, is there something about trusting yourself, trusting your instincts?

C10: Very much so l'd say yes. Essentially it's one thing to be kind of put in a place and be told to do something 
whatever, which isn't, I haven't been forced into therapy before essentially but it's a very different experience to go 'this is what I want to do' and kind of lay it all out and work through it yourself than it is to be kind of told to.

Helpful \& Unhelpful Aspects of participating in the Research

C4: One of the major things that has done that is the ability to gauge my progress over time and being able to look back and say, well compared to how I was. Partly, I suppose a little bit for me was seeing the scores and forms, although that was not the main thing that did it, it was emotionally looking back at how I used to be and how I am now and how experiences have led me through that. I'm not done. I do occasionally have a day when it's bit like a relapse.

\section{References}

Beck, A.T., Ward, C.H., Mendelssohn, M.J. and Erbaugh J. (1961) 'An inventory for measuring depression'. Archives of General Psychiatry, 4:561-571

Beck, A.T., Steer, R.A., and Brown, G.K. (1996) Manual for the Beck Depression Inventory-II. San Antonio, TX: Psychological Corporation

Berne, E. (1961) Transactional Analysis in Psychotherapy. New York: Grove Press

Berne, E. (1966) Principles of Group Treatment. Menlo Park, CA: Shea Books

Berne, E. (1972) What Do You Say After You Say Hello? London: Corgi

Clark, F. (2001) 'Psychotherapy as a Mourning Process'. Transactional Analysis Journal, 31(3): 156-60

Clarkson, P. (1992) Transactional Analysis: an Integrated Approach. London: Routledge

Crossman, P. (1966) 'Permission and Protection'. Transactional Analysis Bulletin, 5(19): 152-4

DeYoung, P. (2003) Relational Psychotherapy: A Primer. New York: Routledge

Erskine, R (1993) Inquiry, attunement, and involvement in the psychotherapy of dissociation Transactional Analysis Journal, 23(4) 184-190

Erskine, R., Moursund, J. and Trautmann, R. (1999) Beyond Empathy: A Therapy of Contact-In-Relationship. New York: Routledge

Erskine, R.G. and Trautmann, R.L. (1996) 'Methods of an Integrative Psychotherapy', Transactional Analysis Journal, 26(4): 316-28
Erskine, R. and Zalcman, M. (1979) 'The Racket System: A Model for Racket Analysis', Transactional Analysis Journal, 9(1): $51-9$

Goulding, M.M. and Goulding, R. L. (1979) Changing Lives Through Redecision Therapy. New York: Grove Press

Hargaden, H. and Sills, C. (2002) Transactional Analysis: A Relational Approach. Hove, Brunner-Routledge

Jacobson, N. S., \& Truax, P. (1991). 'Clinical significance: A statistical approach to defining meaningful change in psychotherapy research'. Journal of Consulting and Clinical Psychology, 59: 12-19

Llewelyn, S. (1988) 'Psychological therapy as viewed by clients and therapists'. British Journal of Clinical Psychology, 27: 223-38.

McNeel, J. (1976) 'The Parent Interview'. Transactional Analysis Journal, 6(1): 61-8

McNeel, J. (2010) 'Understanding the Power of Injunctive Messages and How They Are Resolved in Redecision Therapy', Transactional Analysis Journal, 40(2):159-169

Mellor, K. (1980) 'Impasses: A Developmental and Structural Understanding'. Transactional Analysis Journal, 10(3): 213-22

O'Reilly-Knapp , M. and Erskine,R. G. (2010) 'The Script System: An Unconscious Organisation of Experience' in R.G. Erskine (ed) Life Scripts: A Transactional Analysis of Unconscious Relational Patterns. London: Karnac (pp.291-308)

Sills, C. (2006) Contracts in Counselling and Psychotherapy. London: Sage

Steiner, C. and Perry, P. (1999) Achieving Emotional Literacy. New York: Bloomsbury

Stern, D.N. (2004) The Present Moment in Psychotherapy and Everyday Life. New York: W.W. Norton

Stewart, I. (2002) Transactional Analysis Counselling in Action. London: Sage

Stewart, I. and Joines, V. (1987) TA Today: A New Introduction to Transactional Analysis. Nottingham: Lifespace

Tudor, K. and Widdowson, M. (2001) 'Integrating views of TA Brief Therapy' in K. Tudor (ed) Transactional Analysis Approaches to Brief Therapy. London: Sage (pp.114-35)

Wagner, J. and Elliott, R. (2004) The Simplified Personal Questionnaire. Unpublished manuscript, University of Toledo.

Widdowson, M. (2010) Transactional Analysis: 100 Key Points and Techniques. Hove: Routledge

Widdowson, M. (2011) 'Depression in the frame'. The Transactional Analyst, 1(4): 5-7

Woollams, S. and Brown, M. (1979) TA: The Total Handbook of Transactional Analysis. New York: Prentice Hall 